\title{
Learning to research in distance mode: Technologies for building higher degree research community online
}

\author{
Huw Nolan, Adele Nye, Nikki Rumpca, Ariella Van Luyn \\ University of New England
}

\begin{abstract}
Higher Degree Researchers (HDRs) in Australia tertiary education programs must achieve mastery of complex skills, theories, and concepts. Non-traditional HDRs, especially those enrolled part time and remotely, face barriers to achieving these outcomes. This concise paper uses the case study of a regional university in Australia to investigate the theoretical underpinnings of technology use to promote HDR communities of learning, especially for part time and remote researchers.
\end{abstract}

Keywords: Higher Education, Higher Degree Research, Postgraduate study, online learning communities, Teams, Zoom

\section{Introduction}

While postgraduate research studies can be personally and professionally rewarding, Higher Degree Research candidates (HDRs) face significant barriers to developing mastery in research skills. In Australia, Master of Research candidates must develop "an advanced and integrated understanding of a complex body of knowledge" (Australian Qualifications Framework, Level 9), while doctoral candidates require a "systemic and critical understanding of a substantial and complex body of knowledge at the frontier of a discipline or area of professional practice" (Australian Qualification Framework, Level 10). The barriers to achieving these complex learning outcomes are amplified when research is undertaken remotely, in which case HDRs are disconnected from on-campus facilities and learning communities. Remote learning is often typified by the candidate's flexible research times, mediated by competing time priorities. In this paper, we refer to this group of HDRs as part-time candidates. A recent study that gathered interviews with HDRs learning in distance mode identified community as a crucial enabler of wellbeing (Lister, Seale \& Douce, 2021). This concise paper presents the theoretical underpinnings of an in-progress research project that investigates how to foster HDR learning communities online in Humanities, Arts, Social Sciences and Education at a regional university in Australia. The paper identifies some of the barriers to open and inclusive practice for HDRs enrolled in distance learning mode and describes initial strategies for overcoming them. Because challenges relating to place and time effect HDRs' experience, a hybrid combination of synchronous and asynchronous technologies for building learning communities can aid in better supporting HDRs to experience greater feelings of inclusion and wellbeing.

\section{Case Study Demographics}

The University of New England, based in regional New South Wales, has a long history of providing distance education (Jordan, 2004; University of New England, 2021). This history is reflected in UNE's current student demographics: overall, $84 \%$ of students are enrolled online (UNE Annual Report, 2020). This trend is also reflected to a lesser extent in the HDR enrolment in the Faculty of Humanities, Arts, Social Sciences and Education. Of the 162 HDRs enrolled in the faculty in 2021,101 or $62 \%$ are enrolled off-campus. 47 or $29 \%$ are enrolled part time. COVID-19 has also significantly disrupted the minority of HDRs enrolled on-campus. These demographics mean that a majority of HDRs are not supported by on-campus resources and must also navigate competing time priorities in the case of those enrolled part-time. Therefore, these are the most pressing concerns for the case study.

\section{Part-Time/Off-Campus: Dimensions of Equity and Inclusion in HDR Populations}

A 2020 report documented that HDR completions have more than doubled from 1998 to 2018 (Universities Australia, 2020, p. 78). Yet only 25\% of all doctorate holders work in the tertiary education sector (McGagh et al., 2016, p. 72); presumably, many of these work in a precarious capacity (see for instance, McKenzie, 2021) 
and so, prospects of doctoral graduates are uncertain (Waaijer et al., 2017). It follows that the reasons people commence and complete HDR projects, is not only to pursue careers in academia.

The lack of certainty and therefore motivation to complete, means HDRs, are not completing higher degrees as a necessary means to an end, but rather as an experience in and of itself. Yet for many, the HDR programs are expected to be stressful, and the culture normalises the language of stress, for example, the rhetoric of “"surviving" the doctoral degree" (Byrom et al., 2020, p. 1). Similarly, Postgraduate study often promotes long working hours and prioritises itself over other time commitments (e.g., Metcalfe et al., 2018; Sverdlik et al., 2018). A survey of over 6,000 graduate students revealed the just $42 \%$ of participants indicated an increase in their levels of satisfaction with 76\% saying they spend more than 41 hours per week on their PhDs (Woolston, 2019). However, time is not experienced equally by all people, and so understanding time is crucial for improving the HDR experience.

\section{Temporality in Postgraduate Studies: Non/Linear, Full and Part Time}

Government and institutional mandates for HDR candidate's time to completion represent a barrier to inclusion. Catherine Manathuga (2019) points to the effects of neoliberal agendas in higher education that link time to completion as an indicator of quality; this creates an urgent sense of time-pressure correlated to emotional lows. The Western, one-way, linear progression of time associated with clock time has a disproportion impact on Indigenous, migrant, international and female researchers, whose previous language, and knowledge is often discounted in postgraduate research programs (Manathuga, 2019). The relationship between disability and time is also theorised in disability studies (Kafer, 2013). Irv Zola and Carol Gill coined the ironic term 'crip time' to described that need for 'extra' time often granted as accommodation for students with disabilities (Kafer, 2013). However, Alison Kafer (2013) calls for a reorientation with both notions and time and disability, arguing that disability should not be understood as an impairment; rather, social and architectural barriers are what is disabling. Similarly, notions of 'expected time' are based on particular bodies (Kafer, 2013). Manathuga (2019) calls for different kinds of time in candidature to avoid entrenching social inequalities. She argues for the need for 'lived and opportune time' (kairos) and 'playful-eternal time' (aion). Despite these theorisations, the government stipulations and neoliberal ideologies that regulate these programs leave little space for nonnormative experiences of time.

Arguably in responses to these time pressures, a significant minority of HDRs opt for part time study in Australia, particularly in the Arts, Humanities and Education. In 2018, 43\% of Australian HDRs were part-time (Australia, 2020). Part-time HDRs tend to be older, to have dependents, and to be married (Gopaul \& Gardener 2014). In the Arts, Humanities, Social Sciences and Education, "the average postgraduate student...is more likely to be female, mature aged and part-time" (Johnson, 1995, p. 280). In addition, "part-time doctoral students usually have a full-time paid occupation around which they have to accommodate their doctorates" (Evans, 2002, p.160). Indeed, these competing priorities often lead to higher withdrawals and non-completions (Evans 2002, p.160). Further complicating these vulnerabilities, part-time HDRs are also more likely to be enrolled in distance learning. Wood (cited in Rovai 2003, p.2) reported "over 70\% of recent graduates enrolled in distance education programs were employed in full-time jobs."

Yet—HDRs' experiences enrolled part time are under researched. According to Gopaul and Gardner (2014, p.136), "the literature on doctoral education and the doctoral student experience, in particular, has tended to focus almost exclusively on the full-time student." The literature that does exist suggests part-time HDRs are less engaged (Biegel et al., 2006) and less satisfied (Nettles \& Millet, 2006) than their full-time counterparts. Despite this, most HDR research and initiatives are often designed with full-time researchers in mind (Gopaul \& Gardner 2014). Many HDR programs' in-built assumptions of linear, 'full' time thus represents a significant barrier to inclusion for non-traditional, part time HDRs, such as the cohort at UNE.

\section{Spatiality in Postgraduate Studies: Distance, Isolation and Inclusion}

The days of a higher degree being a 9 to 5 endeavour are long behind us. Today's HDR experience is more flexible, with part-time and off-campus options available. Typically, an on-campus, full-time enrolment is seen as the normative standard. The full-time, on-campus HDR experience is typified by the on-campus community and close relationships with faculty staff and peers (Gardner \& Gopaul 2012). This community is important because HDR learning has enduringly been seen as solitary activity (Douglas, 2020; Holbrook et al., 2014). However, this isolation doesn't necessarily improve the candidate's skill as a researcher and collaboration is 
becoming increasingly more important (e.g. Kompatsiaris, 2021), isolation essential to an HDRs research training.

Isolation is a recurring barrier to HDR's wellbeing, particularly in Arts, Humanities and Education (Batty et.al. 2019; Janta et. al., 2012; Owler, 2010). "Problems of isolation represent one issue which recurs within the literature focusing on the problems experienced by postgraduate students" (Johnson 1995, p. 280). In the Humanities and Education in particular, isolation is exacerbated by discipline norms of working intensively with one or more academic supervisors rather compared to the shared labs in the sciences and applied sciences (Johnson, 1995). Rovai (2003) found that HDRs required, among other things, "social integration, that is...to develop interpersonal relationships with peers, faculty, and staff". A 2021 study found that "isolation was a clear barrier" for HDRs (Lister, Seale \& Douce, 2021). Ryan et al. (2020) use a "jobs demand and job resource" framework to argue that in a high-demand job like postgraduate research, job resources must be in balance with the demands. Job resources include, among other things "support and engagement with peers and the wider scholarly communication" (Ryan et al., 2020, p. 3). When job demands outweigh job resources, HDR workers are likely to become overwhelmed.

The same study found that a high proportion of HDRs identified building community as a significant factor in their wellbeing. Ryan et al. (2020, p. 10) notes that the "highest proportion of HDRs in the present study suggested that improving the workplace culture and creating a greater sense of community or collegiality in researcher networks (as distinct from increasing social engagement and networking opportunities with other HDRs) would positively benefit their wellbeing." An earlier study of HDRs had similar findings. Conrad's (2003, p. 6) study found that the largest group of respondents identified "five ways of enhancing the social and intellectual climate and the research community in which they were working: group supervision, peer support, structured groups, teams, and 'collegialisation' in a broader sense." HDRs themselves identify community building as having a positive effect on their experiences.

However, the relationship between isolation and distance learning is more complicated than might be first assumed. For many HDRs, a low "sense of community, which is related to feelings of disconnectedness and isolation, is believed to adversely affect student persistence in online courses" (Rovai, 2003, p. 4). However, for some HDRs, distance learning does not necessarily equate to isolation; Lister, Seale and Douce's (2021) interviews with postgraduate researchers found that some researchers found large classrooms settings disruptive. Lister, Seale and Douce's (2021) study found that virtual networked spaces such as social media improved HDRs feelings of connectedness and wellbeing. This seemingly contradictory feedback from diverse perspectives suggests that while non-traditional HDRs appreciate a sense of community, traditional classroom and cohort models may not meet their needs, especially given they balance competing time priorities.

\section{In/Formal Learning Communities}

Research clearly indicates that developing research community is crucial in improving HDR experiences, particularly for distance mode researchers. Bensten (2020, p. 157) has stated 'The challenge for the future development of doctoral education is to create and sustain doctoral pedagogies and forms of graduate school leadership that ensure synergy and links between formal, informal and nonformal learning domains.' Conrad (1995, p. 318) argued "that faculty encouragement of the formation of groups within a Master's program provided an environment in which students themselves set up supportive pair or group relationships to enhance their research." This kind of interaction between formal Faculty initiatives and more informal group formation that emerges from these initiatives seems integral.

Sandler and Hall (cited in Conrad, 1995) provide numerous and wide-ranging recommendations for improving research climate. While their study focuses on women in male-dominated research environments, we suggest their recommendations apply to creating an inclusive climate for other vulnerable groups and are still relevant decades later. Sandler and Hall (cited in Conrad, 1995) recommend:

- Versatile modes of communication...to meet varying needs through the development of diverse and complementary groups

- Emphasis...be placed on facilitating the formation of student-initiated support groups rather than merely institutionalising particular group structures

- In supervisor-led groups, supervisors...be especially aware of the effect of their behaviour on women 
- Institutions...assist students to give attention to interaction processes as well as the content or task of the group

- Individuals...be encouraged to develop the ability to play many different roles in groups and use diverse interaction styles

- New technology should be used to improve communication

The faculty can thus effectively play a role in the fostering of HDR-led cohort formation by explicitly creating different, complimentary opportunities for group formation and explicit support in different communication styles and roles in groups. A combination of technology, face-to-face, synchronous, and asynchronous initiatives might facilitate the development of these communities.

\section{Hybrid Learning Environments}

As these studies demonstrate, distance learning - which often attracts part-time HDRs who experience competing time pressures and barriers to access - can be both enabling and isolating. This is particularly true for the UNE cohort in this study, as a result of discipline norms and the 'gendering' of the Humanities and Education. By necessity, technology both enables non-traditional HDRs to learn research skills in distance mode and provides opportunities for communication, at the same time as potentially limiting the likelihood of traditional modes of building learning communities on campus. Indeed, research in the UK has shown the value in focusing technology to promote self-directed learning across a varied student cohort (Mello, 2016). More recently, a review of the literature on technology's ability to improve student retention found that, while there was not an unambiguous correlation between technology use and student retention, learning technologies used judiciously to motivative students and encourage peer-to-peer and peer-to-teacher interaction improve retention (Lassesen, Stenalt, Rossen \& Bager-Elsborg, 2019). As Gopaul and Gardner (2014 pp. 145-6) found, "many of the elements found in the realities of part-time doctoral students can be and are being addressed through technological advancements in curricular delivery at the graduate level." Similarly, Pawlicka-Degar (2021, p. 321 ) challenges traditional thinking about the spatial dimensions for knowledge production and asks: "how do new spaces for humanities inquiry inform new values of scholarly work and transform research practices?" By extension, this begs the question: in what ways can both online and face-to-face (hybrid) learning spaces support HDR's research and learning experiences?

Research (Sullivan \& Freishtat cited in Gopaul \& Gardener, 2014) emphasises graduate students experiences of hybrid learning. "These types of curricular delivery formats recognize the 'nontraditional' elements in these students' lives and can be structured in specific ways to encourage considerable agency for student engagement" (Gopaul \& Gardener, 2014). Gopaul and Gardener (2014) note that Holloway and Alexandre (2012) promoted the use of an inclusive community of learning between faculty and doctoral students with a focus on learnercentred approaches to pedagogy. Undergirding this inclusivity is the notion of individual diversity and the multiple communities to which and in which individuals are committed. More recent research in multiple settings have affirmed these findings citing both the value and challenges of hybrid learning environments for postgraduate learners (Johnson, 2018; Asamoah, 2019; Westerlarkin et al., 2019).

Learning groups made up of HDRs at different stages of their candidature especially gain traction as learning environments are predicated on diversity and inclusion, and, given the apparent elements associated with parttime doctoral student populations, these initiatives are increasingly needed. At UNE, the initial response to these challenges and experiences of HDRs in the Arts, Humanities and Education was to utilise a hybrid synchronous and asynchronous model that used technologies already available to the University: Zoom and Teams.

Understanding how HDRs engage with online learning tools and what is important to online cohorts is key to the successful implementation. Dixon (2010, p.1) reported "there is no particular activity that will automatically help students to be more engaged in online classes". Instead, Dixon recommended multiple modes of interaction to improve student engagement. Buelow et al. (2018) surveyed students $(n=417)$ and concluded that student engagement was best facilitated through thought-provoking questions grounded in real-world situations, opportunities to share one's own opinions and, hearing other people perspectives. Furthermore, and key to our HDR cohort, Buelow et al. (2018, p. 330) recommended the use of "authentic and challenging-but-respectful discussions", following on from Schroeder-Moreno's recommendation of "instructor facilitated, and student owned" engagement (2010, p. 28) 


\section{Synchronous Knowledge Exchange Sessions Using Zoom}

Managing instructor facilitated learning is relatively straight forward, in that it doesn't vary greatly from faceto-face modes of engagement. In 2021, the authors developed a series of monthly 'knowledge exchange sessions', aimed specifically at the learning and research progression of Humanities, Arts, Social Science and Education HDRs. These workshops, run via Zoom, recorded, and shared on the learning management system (LMS) were designed with a process-oriented pedagogy; each workshop addressed an aspect of the development of a research project. The topics were developed in consultation with supervisors, HDR coordinators and HDRs. This latter group identified the need for learning support in publishing journal articles and turning their thesis into a book.

In-keeping with the intention to build research cohort and provided opportunities for communication, the sessions were designed so researchers at different stages of their research development—-both HDRs at different stages of their candidate and postdoctoral researchers and academics - to share their experiences, challenges and insights about each of the organising topics. The sessions, three of which have run at the time of writing this paper, have been attended by a number of HDRs in the faculty. The first session on research questions was attended by 6 and the recording viewed by 26 . The second session on research methodologies was attended by 12 and the recording viewed by 15 . The third session on ethics was attended by 8 and viewed by 3 . Presently, monthly sessions are attended by around 25 people. More fine-grained data about HDRs' experiences of these workshops will be gathered at a later stage of this research project.

In response to COVID-19-related lockdowns, the authors have begun weekly informal catch ups on Zoom, between the monthly knowledge exchange sessions. Catch ups are regularly attended by faculty staff and HDRs providing an environment in which HDRs can ask members of faculty questions regarding their candidature and discuss issues amongst themselves. Although these both the monthly sessions and weekly catch ups are recorded, there is still the issue that non-traditional HDRs might not be available during the working hours of instructors and so cannot attend the synchronous activities.

\section{Asynchronous Networking Using Teams}

There is rapid rise in the use of online learning platforms for asynchronous networking (Trust et al., 2016; Pham et al., 2020). These platforms are often underutilised, Martin et al. (2019) highlighted how award-winning educators take a proactive stance and make the most of the available platforms. One such platform accessible by all UNE staff and HDRs is Microsoft Teams. Platforms such as Teams may appear complicated to some or unsophisticated to others. However, as Pham et al (2020) pointed out, platforms like Teams are simply a natural extension of Vygotsky's (1980) paradigm of learning as a social process. In late 2020 one of the authors worked with the Faculty HDR Representatives to develop an online platform for HDR candidates to alleviate feelings of isolation, build a sense of community and facilitate improved connection and communication. By using Microsoft Teams, engagement was not time dependent which meant that many of our candidates who have expressed competing priorities during normal working hours ( $9 \mathrm{am}$ to $5 \mathrm{pm}$ ), were able to engage. Teams was the preferred choice for asynchronous, student-led engagement because of its, availability to staff and HDRs, flexible functionality, cross device/operating system functionality and a growing usership, Tsia (2018) stated that $41 \%$ of the survey organisations plan to use Teams by the end of 2020).

As opposed to other LMSs such as Moodle, Teams has the benefit that HDRs can dictate how it is used. HDRs can upload files, schedule meetings/hangouts, share screens etc. Rather than an "instructor facilitated, and student owned" engagement tool (sensu Schroeder-Moreno, 2010, p. 28). Teams was envisaged as a student owned and instructor curated tool. Whereby the instructor could moderate discussions if needed, but otherwise HDRs would have full ownership. The author and representatives were responsible for the creation and ongoing curation of the Team space - the 'HASSE HDR Community'. During the initial launch of the site, there was a high level of engagement in the form of posts and sharing of information. Many candidates also attended the informal 'catch up' sessions the representatives hosted in Teams. 


\section{Future Research}

Taking from conservation research, we will adopt and adaptive management framework (see for instance Salafsky \& Margoluis, 2003) of testing, adapting and learning. The next steps will be to survey our HDR cohort to discover what works and what doesn't. This is particularly poignant now considering the impact of COVID19 on face-to-face interactions and the on-the-ground campus community.

\section{Conclusion}

Non-traditional HDRs, often juggling competing demands for their time and enrolled part-time, face barriers to inclusion in HDR communities. Undertaking a postgraduate program in distance learning mode further complicates the temporal dimensions of access and inclusion. These characteristics apply to the HDR cohort at UNE, the case study for this paper. Building HDR community through faculty initiatives that foster HDR-lead group formation is one way of addressing these challenges. Technologies that enable hybrid learning, and a combination of synchronous and asynchronous opportunities to communicate, have the potential to aid in the development of learning communities for distance-mode HDRs. However, further research is needed to understand HDR experiences in these communities and how to better increase engagement with faculty initiatives. While such initiatives have the potential to positive impact HDR's experiences, wider sector change that allows for different kinds of temporal and spatial experiences is also required.

\section{References}

Asamoah, M. (2019). Learner support services for postgraduate students: a qualitative approach. E-Learning and Digital Media, 16(5), 367-392. https://doi.org/10.1177/2042753019860613

Batty, C., Ellison, E., Owens, A., \& Brien, D. (2019). Mapping the emotional journey of the doctoral 'hero': Challenges faced and breakthroughs made by creative arts and humanities candidates, Arts and Humanities in Higher Education, 19(4), 354-376. https://doi.org/10.1177/1474022219844986

Bengsten, S. (2020). Doctoral ecologies and ecological curricula. In R. Barnett \& N. Jackson (Eds.). Ecologies for learning and practice: Emerging ideas, sightings and possibilities (pp. 147-160). Routledge. https://doi.org/10.4324/9781351020268-10

Biegel, D. E., Hokenstad, M. C., Singer, M. I., \& Guo, S. (2006). One school's experience in reconceptualizing part-time doctoral education in social work. Journal of Social Work Education, 42(2), 231-247. https://doi.org/10.5175/JSWE.2006.200400454

Byrom, N. C., Dinu, L., Kirkman, A., \& Hughes, G. (2020). Predicting stress and mental wellbeing among doctoral researchers. Journal of Mental Health, 1-9. https://doi.org/10.1080/09638237.2020.1818196

Conrad, L., \& Phillips, E. M. (1995). From isolation to collaboration: A positive change for postgraduate women? Higher Education, 30(3), 313-322. https://doi.org/10.1007/BF01383755

Department of Education. (2021). Australian qualification frameworks. https://www.aqf.edu.au/aqf-levels

Douglas, A. S. (2020). Engaging doctoral students in networking opportunities: a relational approach to doctoral study. Teaching in Higher Education, 1-17. https://doi.org/10.1080/13562517.2020.1808611

Evans, T. (2002). Part-time research students: are they producing knowledge where it counts? Higher Education Research \& Development, 21(2), 155-165. https://doi.org/10.1080/07294360220144079

Gardner, S. K., \& Gopaul, B. (2012). The part-time doctoral student experience. International Journal of Doctoral Studies, 7(12), 63-78. https://doi.org/10.28945/1561

Gopaul, B. \& Gardener, S.K. (2014). Understanding and supporting part-time doctoral students, Readings on Equal Education in the Twenty-First Century, 27, 135-150.

Holbrook, A., Shaw, K., Scevak, J., Bourke, S., Cantwell, R., \& Budd, J. (2014). PhD candidate expectations: Exploring mismatch with experience. International Journal of Doctoral Studies, 9, 329-346. https://doi.org/10.28945/2078

Holloway, E. \& Alexandre, L. (2012). Crossing boundaries in Doctoral education: Relational learning, cohort communities, and dissertation communities, New Directions for Teaching and Learning, 131, 85-97. https://doi.org/10.1002/tl.20029

Janta, H. Lugosi, P. \& Brown, L. (2012). Coping with loneliness: A netnographic study of doctoral students, Journal of Further and Higher Education, 38(4) 553-571. https://doi.org/10.1080/0309877X.2012.726972

Johnson, E. (2018). Adult learners' perspectives on their engagement in a hybrid learning postgraduate programme, The Journal of Continuing Higher Education, 66(2), 88-105 https://doi.org/10.1080/07377363.2018.1469071 
Jordan, M. (2004). A spirit of true learning: The jubilee history of the University of New England. UNSW Press.

Kafer, A. (2013). Feminist, Queer, Crip, Indiana University Press.

Lassesen, B., Stenalt, M.H., Rossen, D.S. \& Bager-Elsborg, A. (2019). Do learning technologies contribute to reduce student drop-out? A systematic review. In Y. W. Chew, K. M. Chan, and A. Alphonso (Eds.), Personalised Learning. Diverse Goals. One Heart. ASCILITE 2019 Singapore (pp. 169- 177).

Lister, K., Seale, J., \& Douce, C. (2021). Mental health in distance learning: a taxonomy of barriers and enablers to student mental wellbeing. Open Learning: The Journal of Open, Distance and e-Learning, https://doi.org/10.1080/02680513.2021.1899907

Manathuga, C. (2019). 'Timescapes' in doctoral education: The politics of temporal equity in higher education. Higher Education Research and Development, 38(6) 1227-1239. https://doi.org/10.1080/07294360.2019.1629880

Martin, F., Budhrani, K., Kumar, S., \& Ritzhaupt, A. (2019). Award-winning faculty online teaching practices: Roles and competencies. Online Learning, 23(1), 184-205. https://doi.org/10.24059/olj.v23i1.1329

McGagh, J., Marsh, H., Western, M., Thomas, P., Hastings, A., Mihailova, M., \& Wenham, M. (2016). Review of Australia's Research Training System. www.acola.org.au.

McKenzie, L. (2021). The Risks of Precarity: How Employment Insecurity Impacts on Early Career Researchers in Australia. In D. L. Mulligan \& P. A. Danaher (Eds.), Researchers at Risk: Precarity, Jeopardy and Uncertainty in Academia (pp. 115-129). Springer International Publishing. https://doi.org/10.1007/978-3030-53857-6 8

Mello, L. (2016). Fostering postgraduate student engagement: online resources supporting self-directed learning in a diverse cohort, Research in Learning Technology, 24 1-17. https://doi.org/10.3402/rlt.v24.29366

Metcalfe, J., Levecque, K., Wilson, S. (2018). Exploring wellbeing and mental health and associated support services for postgraduate researchers. Vitae. https://re.ukri.org/documents/2018/mental-healthreport /

Nettles, M. \& Millet, C. (2006). Three magic letters: Getting to PhD. John Hopkins University Press.

Owler, K. (2010). A 'problem' to be managed? Completing a PhD in the Arts and Humanities, Arts and Humanities in Higher Education, 9(3)280-304 https://doi.org/10.1177/1474022209356330

Pawlicka-Deger, U. (2021). Place matters: Thinking about spaces for humanities practices, Arts and Humanities in Higher Education, 20(3) 320-338. https://doi.org/10.1177/1474022220961750

Pham, L., McKearney, M., \& Maher, D. (2020). Investigating pre-service teachers' informally-developed online professional learning networks. Australasian Journal of Educational Technology https://doi.org/10.14742/ajet.4766

Ryan, T., Baik, C. \& Larcombe, W. (2021). How can universities better support the mental wellbeing of higher degree research students? A study of students' suggestions, Higher Education Research \& Development, https://doi.org/10.1080/07294360.2021.1874886

Rovai, A. (2003). A practical framework for evaluating online distance education programs, The Internet and Higher Education, 6(2). 109-124. https://doi.org/10.1016/S1096-7516(03)00019-8

Salafsky, N., \& Margoluis, R. (2003). What conservation can learn from other fields about monitoring and evaluation. BioScience, 53(2), 120-122. https://doi.org/10.1641/00063568(2003)053[0120:WCCLFO]2.0.CO;2

Schroeder-Moreno, M. S. (2010). Enhancing active and interactive learning online-Lessons learned from an online introductory agroecology course. NACTA Journal, 54(1), 21-30.

Sverdlik, A., Hall, N. C., Mcalpine, L., \& Hubbard, K. (2018). The PhD experience: A review of the factors influencing doctoral students' completion, achievement, and well-being. International Journal of Doctoral Studies, 13(1), 361-388. https://doi.org/10.28945/4113

Trust, T., Krutka, D. G., \& Carpenter, J. P. (2016). Together we are better': Professional learning networks for teachers. Computers \& Education, 102, 15-34. https://doi.org/10.1016/j.compedu.2016.06.007

Tsai, P. (2018). Business Chat Apps in 2018: Top Players and Adoption Plans. The Spiceworks Community. [Online]. https://community.spiceworks.com/blog/3157-business-chat-apps-in-2018-top-players-andadoption-plans

Universities Australia (2020). Higher education: facts and figures. Universities Australia

University of New England (2020). Annual Report https://www.une.edu.au/ data/assets/pdf file/0004/375871/UNE-Annual-Report-2020-Narrative.pdf

Waaijer, C. J., Belder, R., Sonneveld, H., van Bochove, C. A., \& van der Weijden, I. C. (2017). Temporary contracts: Effect on job satisfaction and personal lives of recent $\mathrm{PhD}$ graduates. Higher Education, 74(2), 321-339 https://doi.org/10.1007/s10734-016-0050-8

Westerlarkin, M., Christiaans-Dingelhoff, I., Filius, R., de Vries, B., de Bruijne \& van Dam, M. (2019). Blended learning for postgraduates; an interactive experience, BMC Medical Education, 19(289), n.p https://doi.org/10.1186/s12909-019-1717-5 
Woolston, C. (2019). PhDs: The tortuous truth. Nature, 575, 403-406. https://doi.org/10.1038/d41586-01903459-7

Vygotsky, L. S. (1980). Mind in society: The development of higher psychological processes. Harvard university press. https://doi.org/10.2307/j.ctvjf9vz4

Nolan, H., Nye, A., Rumpca, R., \& Van Luyn, A. (2021). Learning to research in distance mode: Technologies for building higher degree research community online. In Gregory, S., Warburton, S., \& Schier, M. (Eds.), Back to the Future-ASCILITE '21. Proceedings ASCILITE 2021 in Armidale (pp. 177-184).

https://doi.org/10.14742/ascilite2021.0125

Note: All published papers are refereed, having undergone a double-blind peer-review process.

The author(s) assign a Creative Commons by attribution licence enabling others to distribute, remix, tweak, and build upon their work, even commercially, as long as credit is given to the author(s) for the original creation.

○) Nolan, H., Nye, A., Rumpca, R., \& Van Luyn, A. 2021 